\title{
Uma abordagem semiótica e indicial da identidade na era de YouTube
}

\section{Fernando Andacht}

Doutor; Universidade Tuiuti do Paraná

fernando.andacht@fic.edu.uy

\section{Resumo}

O artigo estuda os efeitos comunicacionais e imaginários produzidos pelos vlogs, quer autênticos, quer falsos, no YouTube através de alguns casos célebres na história desse site para carregar e compartilhar vídeos. Em muitas dessas produções audiovisuais há um predomínio dos signos indiciais a classe de significação que surge do contato do signo com seu objeto, como as pegadas ou os sintomas. Na época atual, estes signos são muito procurados pelos públicos para satisfazer o interesse coletivo por um corpo a corpo com os realizadores amadores - ou aqueles que se apresentam assim - de vlogs autobiográficos. A abordagem teórica da semiótica triádica de Peirce é usada para a análise da identidade humana na era da internet, e também para uma análise da dúvida sobre o autêntico e seu oposto, o simulado, um elemento inseparável dessa experiência midiática.

\section{Palavras-chave}

YouTube. Semiótica. Identidade. Autenticidade. Fraude.

\section{Introdução: a virada indicial na era das novas tecnologias}

A chamada "virada linguística" reúne os estudos do século XX sobre a influência da linguagem verbal na representação (a dimensão simbólica), desde o cinema, através de desenhos animados até a pintura; depois chegou a "virada pictórica", que se encarregou de analisar o significado cultural das imagens (a dimensão icônica). Minha proposta neste artigo é que este é o momento para realizar um estudo da "virada indicial", qual seja, a análise das representações da mídia que exibem um amplo e variado leque de evidências, de elementos de prova em relação à vida cotidiana (a dimensão indicial), através de uma vasta gama de gêneros e formatos audiovisuais. 0 universo do indicial-mediático é muito hetero- 
gêneo na atualidade, este inclui não apenas os reality shows com suas múltiplas plataformas, mas também as redes sociais como Facebook, e de modo marcante esse imenso depósito de vídeos digitais amadores que coexistem de modo promíscuo e caótico com inúmeros arquivos audiovisuais da história do cinema e da TV, qual seja, o site YouTube. Essa espécie de museu contemporâneo do visual-indicial está sendo constantemente organizado de modo arbitrário e espontâneo, pessoal e comercial. A análise dessa imensa documentação banal e sublime pertence a esta 'virada indicial'. ${ }^{1}$ Em alguns estudos da recepção midiática (ANDACHT, 2004; 2005), procurei demonstrar que quando o público observa as expressões de emoções de pessoas comuns que eles consideram como não sendo roteirizadas ou ensaiadas, e, portanto, como um comportamento de tipo espontâneo, próximo do fisiológico - exatamente o contrário do que acontece na ficção - os espectadores anseiam ter uma experiência de autenticidade. Essa constatação me levou a formular a seguinte pergunta: qual elemento haveria no mecanismo semiótico da representação da mídia baseada no factual contemporâneo que possa explicar a procura dessa experiência singela?

A base da minha abordagem encontra-se na dimensão factual e indicial da significação, uma das três dimensões desenvolvidas como centrais no modelo semiótico de Peirce; estas estão em estreita relação com as três valências que, conforme o lógico, constituem toda experiência possível. A hipótese é que a poderosa atração que exercem os diversos gêneros documentais da realidade cotidiana mais corriqueira é o resultado da prevalência de signos que possuem uma ligação existencial com seu objeto, quais sejam os índices ou signos indiciais. Desde o clássico cinema documentário, até os três vlogs autobiográficos do site YouTube que analisarei aqui, todos estes artefatos audiovisuais produzem seu efeito específico através de "[...] um Signo cujo poder de significar seu objeto deve-se a que ele possui uma Relação genuína com aquele Objeto." (CP 2.92, PEIRCE, 1931-1958). ${ }^{2}$ Porém, em função da natureza triádica da semiótica peirceana devemos levar em conta os outros dois modos de ação de todo signo: o aspecto qualitativo, que é próprio do signo icônico e que lhe permite funcionar como sendo semelhante a seu objeto, como é o caso das imagens, e a dimensão geral ou convencional, que caracteriza o signo simbólico, próprio da linguagem verbal, por exemplo. Adotarei a premissa de que a relação da mídia com a representação do factual, seja na mídia tradicional ou na mais atual - como as redes sociais - envolve uma

\footnotetext{
${ }^{1}$ Há antecedentes da virada indicial na cultura literária, pictórica e oral nos escritos de Ginzburg (1983), e na obra de Ford (1994), que desenvolveu os estudos do que Ginzburg chamou de "paradigma indiciário".

${ }^{2}$ Vou citar a Peirce do modo convencional: 'x.xxx' corresponde ao volume e ao parágrafo da edição dos Collected Papers (19311958).
} 
combinação complexa e em mutação contínua de imagens, de evidência factual e de linguagem verbal.

Estudar as fronteiras dos gêneros no cinema ou nas redes sociais supõe o esforço por compreender como aquelas funcionam semióticamente. No caso do factual-audiovisual, o mecanismo semiótico baseia-se no predomínio instável, mas conspícuo de uma das três dimensões da significação, qual seja, a factual/indicial, em relação às outras duas, a qualitativa/icônica e a geral/simbólica. 0 objetivo específico da presente análise é descrever de modo sistemático o efeito semiótico que produz o corpo que se expressa de modo espetacular, isto é, em vez da fala que informa e persuade os espectadores sobre algo, estamos perante a expressão irresistível e aparentemente incontrolável das emoções mesmas (sem a intervenção da fala). 0 fato de alguém ficar vermelho (de vergonha), chorar, soluçar ou exibir um tremor, é considerado um índice fisiológico pela audiência, na sua procura de testemunhos genuínos no site do YouTube. Tais signos indiciais seriam a garantia decisiva da autenticidade dessa experiência comunicacional, a causa de sua natureza mais fisiológica que cultural/convencional. Essa classe de efeito na audiência dos gêneros factuais constitui o elemento distintivo deles, o que os diferencia da ficção, por exemplo, da novela televisiva.

Se falarmos de efeitos de sentido, é preciso introduzir a noção peirceana do interpretante. Em vez de o significado ser uma das duas faces de uma folha, uma concepção espacial estática e preestabelecida, como no modelo saussuriano, a natureza do signo interpretante é processual: trata-se de um efeito gerado pelo signo ao longo do tempo, e que por ter natureza sígnica, ele também tem o poder de gerar outros signos. Conforme esta noção, a ação dos signos ou semiose é autônoma (RANSDELL, 1989); o interpretante é um elemento lógico, a noção refere-se à interpretação e não à pessoa que interpreta, qual seja o intérprete. A semiótica não nega a intervenção humana no processo interpretativo, nem no uso geral dos signos, mas essa teoria tenta nos explicar a significação sem recorrer ao psicologismo; tratase de uma análise lógica do sentido. 0 modelo peirceano propõe no nível fundamental uma série de acontecimentos (DEBROCK, 1991): alguma coisa acontece pela intervenção de signos, cuja função primordial é revelar seu objeto parcial e falivelmente no eixo temporal:

Um signo, ou representamen, é algo que está para alguém em lugar de outra coisa em algum aspecto ou capacidade. Ele se dirige a alguém, isto é, cria na mente dessa pessoa um signo equivalente, ou talvez um signo mais desenvolvido. Esse signo que o signo cria eu o denomino o interpretante do primeiro signo. 0 signo representa (stands for) algo, seu objeto. (CP 2.228, PEIRCE, 1931-1958). 
O pesquisador canadense Erving Goffman (1959) foi pioneiro no estudo das interações que se desenvolvem quando as pessoas estão face a face, no âmbito social que ele chamou de "ordem de interação". Nesse espaço ritual da sociedade acontece uma troca de signos cujo intuito é legitimar nossa presença; esta abordagem complementa a proposta de estudar o sentido a partir de seus efeitos visíveis na vida de cada dia. Há mais de meio século, a partir do estudo micro-sociológico, Goffman definiu o self 3 enquanto cerne da identidade humana, algo que imaginamos estar localizado no mais profundo do cérebro (ou do peito, perto do coração), como um elemento externo, exosomático, cuja natureza é a de uma imagem ou personagem encenado que faz parte de um processo social interativo, e que, por tal motivo, não estaria nunca definido completamente. 0 self é posto em cena no âmbito da interação humana, o espaço onde a identidade será convalidada (ou não) pelos outros:

Neste informe o self encenado (performed self) foi considerado como uma classe de imagem, que normalmente goza de credibilidade (creditable) ... Enquanto essa imagem é considerada em relação ao indivíduo, de tal maneira que um self lhe seja atribuído (imputed), o self mesmo não deriva de seu possuidor, mas da totalidade da cena de sua ação, sendo gerado por esse atributo dos acontecimentos locais que os faz interpretáveis por testemunhas. Uma cena corretamente realizada e atuada leva a audiência a atribuir um self ao personagem atuado, mas esta atribuição - este self- é um produto de uma cena bem sucedida, e não é a causa dele. (GOFFMAN, 1959, p. 252)

Na citação, Goffman descreve o self imputado ou atribuído, ${ }^{4}$ qual seja, a identidade tal como ela é interpretada pela comunidade, na ordem da interação, onde o fator básico é o encontro face a face. Na atualidade, o self imputado está cada vez mais mediatizado pelas redes sociais, e pode ser equiparado à noção de interpretante semiótico. Este é o sentido legítimo, acreditável, que surge, por exemplo, de nosso modo de lidar com os signos próprios nas mídias, de nosso desempenho dramatúrgico-ambiental, o qual não é (necessariamente) um engano, como de fato acontece com a apresentação de uma pessoa em um dos casos do YouTube usado neste texto. A análise goffmaniana propõe colocar no exterior da pessoa aquilo que parece ser o elemento mais interior ou íntimo; a antiga noção da alma

\footnotetext{
${ }^{3}$ Há uma tendência crescente nas ciências sociais, e particularmente em algumas áreas da Psicologia acadêmica, a usar o termo inglês, 'self , em vez da tradução portuguesa 'si mesmo' ou 'eu'. Neste artigo vou adotar essa prática.

${ }^{4}$ Eu estive durante um longo tempo refletindo sobre a melhor tradução possível do termo inglês imputed e inclusive cogitei usar a palavra 'acreditado', porque uma parte do significado do verbo 'acreditar' inclui o sentido "considerar como verdadeiro, aceitar, admitir". Penso que esse conceito - 'imputado' - também serve para descrever a proposta de Goffman no que diz respeito às pessoas serem convalidadas pelos outros que elas encontram na ordem de interação, e que esse resultado depende de seu esforço dramatúrgico. Não obstante, seu modelo teórico não supõe que o mundo esteja povoado exclusivamente por farsantes, nem que eles sejam a maioria na sociedade. A tese principal de Goffman propõe que aquilo que pensamos seja possuído por nós como se fosse um bem material localizado em nosso interior, é em realidade um elemento externo, local e transitório, algo que devemos continuar procurando ao longo de toda nossa vida no âmbito da ordem de interação.
} 
hoje é conceptualizada em termos psicológicos como o self. Portanto a alma como self não é mais do que um signo em constante desenvolvimento (COLAPIETRO, 1989). A tradicional noção é inseparável de nossa infindável tentativa de produzir uma certa representação de nós mesmos, a qual receberia idealmente a aprovação de outrem, mas, no caso de falhar, recebe-se o julgamento negativo, a punição do descrédito; nesse caso, a pessoa sofre pela ignomínia de ser considerada um impostor pelo outro que a enfrenta e desacredita.

As chamadas novas tecnologias da comunicação só conseguem tornar ainda mais complexo um mecanismo muito antigo, que se relaciona ao teatro através das noções de 'personalidade' e de 'pessoa'. Ambas as noções provêm etimologicamente daquelas máscaras teatrais que exprimem a euforia e a disforia, próprias da comédia e da tragédia. Fotografias, tweets, canções ou videoblogs (vlogs) virais, tudo é útil para encenar e atuar corretamente a cena identitária, no Facebook, no YouTube ou em outros sites. Esse comportamento nos aproxima e nos afasta sem cessar uns dos outros, sem importar onde estejamos instalados fisicamente no mundo.

Alguns desses efeitos, no caso particular de YouTube, podem ser quantificados ou descritos qualitativamente - refiro-me aos numerosos comentários que com frequência suscita um vídeo. Podemos focar semióticamente cada glosa escrita sobre os vídeos que de modo típico parodiam outro vídeo como se fossem um interpretante concreto dessas imagens e sons. As abundantes glosas são signos mais desenvolvidos dos vlogs populares que comoveram e agitaram essa comunidade pelas suas características indiciais, como tentarei explicar agora.

\section{Três vlogs iniciais e indiciais: entre a densidade testemunhal e a leveza icônica}

Meu corpus consiste em três vídeos inaugurais que lançam no ciberespaço três cronistas femininas; através de confessionários domésticos e cotidianos, elas alcançam uma grande repercussão. Duas delas provêm dos Estados Unidos e a outra, da Argentina.

O primeiro envio de vlog de uma adolescente, cujo apelido ou 'nick(name)' é lonelygirl155 tem o título "Primeiro blog/A inépcia social prevalece" (Dorkiness prevails ${ }^{6}$ ); isso

\footnotetext{
${ }^{5}$ Literalmente o apelido ou nick significa 'jovem solitária de quinze anos'.

${ }^{6} \mathrm{O}$ termo 'dork' é difícil de traduzir em português, ele denota um comportamento pouco sociável, que exibe inépcia nas diversões da vida, a causa de um excesso de seriedade, de tempo dedicado ao estudo, etc. A palavra inglesa 'nerd' se tornou popular através de séries televisivas como The Big Bang Theory, cujos heróis encarnam esse estereótipo, e a atitude dessa classe de personagem pode ser descrita com a palavra 'dork'.
} 
acontece no dia 16 de junho de 2006, no verão boreal. Nove anos e milhões de visitantes mais tarde, seu vlog continua suscitando comentários polêmicos. Junto com o fascínio causado por essas imagens imperfeitas, claramente não profissionais, há no título do vlog da lonelygir15 um anúncio saboroso, que tem afinidade com um princípio estético e ético que rege na comunidade Youtubense, e que esse primeiro relato autobiográfico confirma: tratase do culto da espontaneidade. A produção audiovisual revela diversas falhas, possui o elemento humano e improvisado, em nítido contraste com a perfeição das imagens industriais feitas em Hollywood.

Em cada gesto, a moça que se apresenta como 'Bree' e diz ter 16 anos, parece muito insegura: ela se abraça aos joelhos e inclina a cabeça para os lados. Bree vacila ao procurar a próxima palavra, sem deixar de suspirar, o tremor de seus lábios nervosos sua condição de enunciadora amadora e temerosa no universo de YouTube, apesar da sua fala engenhosa. 0 visível desassossego cria uma aura cativante ao redor da jovem. O fato de ela encolher os ombros regularmente produz a impressão de que Bree está pedindo desculpas o tempo todo, como se ela nos dissesse: isto para mim é dificílimo, e eu estou fazendo o melhor que posso. A imagem é emblemática de uma adolescente na era da confissão insegura nas redes sociais.

Toda a obra de Goffman pode ser lida como se fosse uma aguda e sistemática reflexão sobre o dilatado catálogo dos deslizes e acidentes que estão à espreita na sempre vulnerável ordem da interação. Quando algo na apresentação de si mesmo sai mal, isso nos faz merecedores da pertença ao pouco prestigioso clube dos desajeitados, e ninguém é mais sensível e vulnerável com respeito a essa classe de acidente no âmbito da interação que uma adolescente como Bree, que alega ter 16 anos, embora seu apelido mencione o fato de ser uma jovem (solitária) de quinze anos ('lonelygirl15'). Por isso é interessante que ela não apenas fale desse temor, qual seja a ameaça do desajeitamento no título de seu primeiro vlog, mas também encene isso corporalmente, com um humor baseado numa baixa autoestima exagerada, hiperbólica.

Os eloquentes e reiterados signos corporais e indiciais de desconforto de Bree contrastam fortemente com sua presença magnética, uma mistura irresistível de ingenuidade e de charme. Ela não fornece dados muito específicos sobre sua vida e explica essa omissão: 
ela quer manter afastados os possíveis assediadores entre os visitantes de YouTube. ${ }^{7}$ Há uma grande densidade visual no vlog da jovem que escolhe se apresentar com um signo de identidade composto: a idade e o sentimento aparecem juntos em seu nick "jovem-solitáriade-quinze-anos". 0 signo não apenas a identifica, mas também revela seu estado de ânimo. Esse é o documento de identidade duplamente ambíguo com o qual Bree tornou-se célebre no universo das redes, porque não é essa a idade que ela mesma afirma ter no primeiro vlog; e o apelido com o qual ela se apresenta nos vlogs de YouTube corresponde a diversos nomes próprios (Brenda, Sabrina, Bridget, Rebecca...).

No mês de setembro de 2006, após milhares de compartilhamentos, Bree foi identificada e exposta em várias mídias como a atriz iniciante australiana de 19 anos Jessica Rose. A polêmica sobre sua possível fraude ocupou muitas páginas do jornal The New York Times, inclusive antes de a fraude ser descoberta. No dia 23 de agosto daquele ano, a colunista Virgina Heffernan enviou uma mensagem electrónica a Bree, na qual lhe perguntou "como foi que ela chegou a criar seu vlog". A jornalista comentou a resposta recebida admirada: "Mas digam-me se isto não lhes parece verdadeiro", e na continuação ela transcreveu a mensagem recebida. Com efeito, o relato sobre a origem deste diário-vídeo no YouTube consegue duplicar verbalmente a tímida gestualidade adolescente e feminina que se pode observar no vlog: saturado de expressões verbais juvenis, seu texto evidencia autenticidade, sobretudo quando Bree conta detalhes do cotidiano atípico de uma filha única educada na sua casa por pais religiosos estritos - o controverso modelo de educação chamado 'home schooling', na América do Norte. Da extensa mensagem de Bree transcrita pela jornalista do The New York Times, gostaria de resgatar uma frase que se aproxima bastante da realidade, embora tempos depois descobriu-se que o comentário fazia parte de uma sofisticada fraude comercial: "Eu comecei a assistir a vídeos há alguns meses, depois de que (seu amigo) Daniel envioume um vídeo feito por paytotheorderofofof2"8. A autora desses diários-vídeos identifica-se

\footnotetext{
${ }^{7}$ Seus vinte e cinco vídeos recebem nos primeiros três meses "[...] entre 200.000 e 600.000 visitas, e se colocam regularmente no lugar mais alto da lista dos 'Mais Assistidos' de YouTube [...]", eles têm assim "[...] uma audiência pela qual muitos executivos da TV a cabo estariam dispostos a matar." (RUSHFIELD; HOFFMAN, 2006, doc. não paginado). Sobre o escândalo ver também o artigo de Foremski (2006).

${ }^{8} \mathrm{O}$ nick da autora do vídeo que supostamente inspirou a série de vídeos da lonelygirl15, é 'paytotheorderofofof2', o qual é um trocadilho. A autora dos vlogs usou como base em seu nick uma frase financeira convencional, "pay to the order of", que aparece nos cheques na América do Norte, e serve para designar o destinatário da soma escrita no cheque, algo assim como 'pague-se a soma de dinheiro X a Fulano'. Neste caso a brincadeira é dupla: na frase não aparece nunca essa pessoa, o destinatário do pagamento, e multiplica-se a preposição 'of' que deveria ser seguida do nome dessa pessoa. E em vez do nome aparece o número ' 2 ', cujo som é igual ao da preposição 'to', que introduz o destinatário do pagamento, em outra frase desse tipo (Payable to). O mecanismo humorístico fundamental é o uso de uma construção convencional do mundo econômico para apresentar vídeos sobre a vida pessoal, comentários íntimos que são o oposto completo do outro universo de discurso. Essa classe de humor própria dos adolescentes (e das crianças) é um ingrediente próprio do âmbito audiovisual amador do YouTube.
} 
com um nick, como Bree, mas ela era autêntica, e tinha um público bem menor do que a jovem que assina seus vídeos 'lonelygirl15'.

Além da sólida e material atração indicial ou 'index appeal' (ANDACHT, 2005) dos vlogs de Bree, deve-se mencionar os aspectos qualitativos ou icônicos de seus vlogs, os quais exercem uma grande atração entre visitantes e críticos. Vale a pena lembrar que, conforme Peirce, o signo icônico não tem como função primordial a semelhança, mas o elemento sensível na significação, qual seja, o poder de encarnar qualidades que pertencem de modo natural e inegável ao signo considerado em si mesmo, seja este interpretado ou não: "Um ícone é um representamen daquilo que representa e para a mente que o interpreta como tal, em virtude de ser uma imagem imediata, qual seja, em virtude de caracteres que lhe pertencem a ele mesmo como um objeto sensível." (CP 4.447 PEIRCE, 1931-1958, tradução nossa). Mesmo depois da descoberta da identidade verdadeira da jovem atriz que personificou a adolescente Bree, os leves aspectos icônicos dos vlogs continuam sendo atraentes para os visitantes, e de algum modo servem para compensar os índices ausentes, tal como acontece, por exemplo, numa típica novela na televisão.

\section{0 modelo indicial do famoso vlog icônico e fraudulento}

O extenso e humorístico nick mencionado como a razão do interesse de Bree pelo site da internet refere-se a uma jovem de 17 anos que se apresentou como 'Emily'. Ela é a criadora de um vlog que conta sobre seu cotidiano em termos muito corriqueiros, e o faz de um jeito extremamente simples. Seu primeiro vlog leva o modesto título de "Blog 1", e foi colocado no YouTube, no dia 24 de maio de 2006. Vale a pena comparar essa produção amadora da jovem americana Emily com os vídeos colocados por Bree pouco tempo depois. Nas produções de vídeo de Emily há silêncios incômodos, abundante hesitação e as imagens têm cores saturadas, pouco nítidas, mal definidas devido à imperfeita iluminação. É impossível não perceber todos esses problemas no vlog inicial de paytotheorderofofof2. Porém aquilo que parece mais interessante para a análise proposta é um movimento nervoso, quase um tique corporal que faz com que o torso da adolescente fique sacudido, como se uma força externa a ela mexesse com seu corpo de modo rítmico e incontrolável. Por isso, durante o breve minuto e meio de duração do vídeo, torna-se difícil para o espectador duvidar do esforço genuíno, autêntico da vlogueira, para poder compartilhar algo de sua vida de cada dia com esse público invisível de YouTube. Emily luta com todas suas forças para vencer a potente barreira de sua evidente timidez. 0 tom e os gestos de Emily cobrem sua humilde crô- 
nica com um leve, mas perceptível, manto indicial de insegurança sobre o que falar e como falar; ela não parece ter a convicção de que isso que ela quer nos contar valha a pena, porque talvez seu relato autobiográfico interesse pouco ou nada aos eventuais visitantes de seu vlog no YouTube. Esse modesto e caseiro testemunho nos convida a um espaço privilegiado na era da virada indicial: o âmbito (antes) restrito dos bastidores da cena microsocial. Tratase da região que Goffman (1959) chamou de 'backstage', ou seja, uma das regiões na qual se prepara a cena da performance social. 0 conceito de bastidores ou backstage refere-se a "[...] um espaço relativo a uma determinada performance, onde a impressão promovida por esse desempenho social é contradita de modo ciente como algo normal" (GOFFMAN, 1959, p. 112), e essa atitude estaria revelando um tipo de performance mais 'sincera' em uma região normalmente oculta da interação social.

O efeito de máxima honestidade que produz o suposto acesso ao backstage provém do fato de que usualmente há obstáculos físicos para que os olhos e ouvidos estranhos não tenham acesso a essa região, onde as aparências são ensaiadas, preparadas para depois serem exibidas na região frontal ou fachada (front) da interação social.

"O apetite pela realidade não tem diminuído, mas continua a ser uma fome instável, contraditória, composta de dúvida e credulidade, a vontade de acreditar e o desejo de ser iludido." (SCOTT, 2010). A frase pertence ao principal crítico de cinema do The New York Times, que publicou um ensaio com uma iluminadora reflexão sobre uma das modas duradouras do ainda novo século 21, qual seja, a tendência audiovisual relativa às diversas formas de representação da realidade. Essa inclinação explica a produção dos novos documentários, dos quase-documentários, e dos filmes de ficção que sem pudor exploram e parasitam algumas das características distintivas de um gênero que tradicionalmente foi sério e minoritário, do ponto de vista ético e comercial. Suas observações, Scott (2010) afirma, poderiam "[...] ser aplicada ao âmbito da política e da mídia em geral [...]” (ibidem), e esse ensaio serve também para a reflexão sobre a proliferação de vídeos autobiográficos e amadores no YouTube.

O mais importante não é apenas o fato existencial de essas imagens serem autênticas ou fraudulentas, mas a motivação principal do público para conferir, observar e concluir a partir de sua hesitação, da autêntica dúvida sobre, por exemplo, a autenticidade da fala ou mesmo da identidade da pessoa que faz um vlog sobre sua vida. Essa oscilação descrita pelo crítico cinematográfico Scott (2010) constitui o motor que leva os espectadores do site a assistir aos vídeos para depois escrever seus comentários no espaço dedicado a exibir as 
opiniões - uma versão moderna do 'water cooler effect', qual seja, as falas corriqueiras no lugar de trabalho sobre o que foi assistido na mídia, tipicamente pela maioria ou por muitas pessoas - como acontece com as novelas no Brasil - no momento da pausa laboral (por isso a referência ao refrigerador de água num escritório). Durante o intervalo do cafezinho real ou virtual debate-se o grau de realidade ou de ficção de produções audiovisuais aparentemente amadoras no YouTube, como as de lonelygirl15 ou de paytotheorderofofof 2.9

Oferecer um acesso massivo ao refúgio onde tradicionalmente foi construída com o maior cuidado possível nossa apresentação na região frontal, a fachada da interação constitui o prato principal do banquete indicial midiático: "Os dormitórios e os banheiros são talvez os principais espaços de proteção na sociedade anglo-americana, os banheiros possuem um especial interesse neste livro porque em muitos lares são os únicos quartos onde a pessoa solitária pode trancar-se de forma adequada." (GOFFMAN, 1963, p. 39). Tanto o vlog da Emily, o modelo mencionado por sua fã ficcional Bree, quanto o desta última, encenam suas narrativas no quarto de dormir das cronistas. De modo paradoxal, elas nos falam instaladas num espaço doméstico discreto que as resguarda daqueles com quem elas convivem, para assim receber inumeráveis olhares de desconhecidos, que provêm de qualquer lugar do mundo.

O contraste entre os dois vlogs, o autêntico e o simulado, é semelhante ao contraste que existe entre uma cena de amor num documentário feito conforme o estilo do 'direct cinema' - um gênero fílmico que se caracteriza por encarnar a tentativa do realizador de virar uma mosca-na-parede - e outra cena também de estilo romântico, mas produzida num reality show, com uma discreta ou dissimulada, porém considerável, equipe de produção. Observar a jovem do vlog genuíno que supostamente inspirou Bree, conforme seu testemunho, permite compreender as desconfianças surgidas do início da saga da Youtuber apelidada lonelygirl15. Cada vídeo de Bree, como foi revelado algum tempo depois, foi cuidadosamente editado e fabricado por uma equipe oculta em um quarto que não era o seu, mas do produtor. Por isso, assistir depois a um vlog de Emily/paytotheorderofofof2 é como perder boa parte da intensidade da luz e da nitidez do som, e junto com isso uma boa parte da potência vital da confissão cheia de graça e airosidade de lonelygir15.

\footnotetext{
${ }^{9}$ Quase uma década depois desses primeiros vídeos, a autora continua carregando vídeos no YouTube, e recentemente ela mudou sua identidade nesse site - ela agora é sortaspooky - e criou um novo canal para seus vlogs. Sua imagem atual é radicalmente diferente, além do fato dela ser uma adulta jovem, Emily tem o cabelo laranja-vermelho, vários piercings no nariz e nos lábios. $O$ novo nick é um trocadilho com o adjetivo 'assustador', literalmente seria 'um pouco assustador', provavelmente em alusão a sua imagem e ao fato dela ter confessado em 2010 ser gay.
} 
Talvez por esse motivo seja credível um relato sobre a curiosa reação de um fã desta última. Depois da exposição da real identidade da atriz australiana, de ser amplamente conhecida pelo público a natureza da requintada falcatrua realizada durante meses pelos membros da produção, alguém que acostumava escrever regularmente a Bree enviou uma mensagem com a seguinte questão: "o fã queria saber se durante todo esse tempo ele esteve falando com a jovem mulher chamada Jessica Rose". A resposta lhe foi enviada pela pessoa cuja tarefa profissional na equipe de produção de lonelygirl15 era responder a abundante correspondência diária em seu nome: ela lhe disse que não, que até então ele tinha falado com a Bree: "Se você quiser falar com Jessica Rose, você pode ir a seu site no MySpace. Se você quiser continuar falando com Bree, você deve usar este endereço eletrônico". Considero que o mais interessante dessa troca foi a resposta dada pelo visitante dos vlogs: "Acho isso razoável (Fair enough)". O visitante não apenas aceitou como algo normal a esquisita situação, como também depois passou a contar a Bree as últimas novidades de sua vida, conforme narra a revista Wired, no seu número de dezembro desse ano (DAVIS, 2006).

\section{0 estranho caso de uma jovem vlogueira histriónica e autêntica}

0 que têm em comum as pessoas que assistem a vídeos como os de paytotheorderofofof2 e os de lonelygirl15 ou aos inúmeros formatos de reality shows e alguém como o usuário impassível dos vlogs de Bree que continuou a dialogar com alguém que ele já sabia que_nunca existiu, é o anseio por conferir primeiro, e eventualmente confiar na autenticidade daquilo que no começo parece ter a garantia de abundantes signos indiciais; essa classe de comportamento não acontece na relação do espectador com a ficção.

Um fenômeno semelhante aconteceu também no YouTube, mas teve uma origem geográfica originária na Argentina, muito longe da procedência dos outros dois vlogs. Sua protagonista foi uma mulher jovem que no ano 2008 postou seu primeiro vlog de tom também intimista; nele ela exibiu com humor, e com aparente sinceridade, sua mágoa pelo ainda recente fim de uma relação amorosa. Assim iniciou-se a série de vídeos cujo título ousado e provocante transformou-se na identidade da vlogueira: "La loca de mierda" (A maluca de merda). ${ }^{10}$ Trata-se de uma série de testemunhos de tom humorístico e idiossincrático de uma jovem mulher argentina chamada Malena Pichot, que se coloca perante a câmera web

\footnotetext{
${ }^{10}$ A expressão "loco/a de mierda" pertence à gíria do Río de la Plata, seu significado é menos um xingamento ou uma frase sexista, como é o caso da frase "histérica de...", mas funciona com ambos os gêneros como uma forma coloquial, um pouco grosseira usada pelos jovens para enfatizar uma atitude fora do convencional ou engraçada, irresponsável, etc.
} 
de seu computador, falando e gesticulando com mais de um toque histriônico em diversos lugares da casa; o conjunto é iluminado de modo bastante imperfeito - a marca certa do vídeo amador. ${ }^{11}$ No primeiro vlog, assistimos a uma cena bem conhecida da ficção, mas ela tem características inegáveis de uma produção doméstica, do que se reconhece como o real espontâneo, a vida não roteirizada. A improvisada cronista de sua deprimida cotidianidade está vestida com um roupão de banho nada elegante nem sedutor; ela não tem maquiagem. Não há dúvida alguma para o espectador de que a jovem mulher não está muito apresentável. Suas expressões ficam muito coladas ao corpo, por exemplo, o choro incontrolável, enquanto ela se lamenta amargamente do término de sua relação sentimental: "Meu Deus, gordo eu tenho saudade de você!” (¡Ay, gordo por Dios te extraño!). Logo depois, ela conta com calma pelo telefone que, felizmente, ela já superou a crise emocional da separação. Nesse caso, a criação do vídeo inicial no qual Malena Pichot revelou sua intimidade foi considerada autêntica - se usarmos a entrada na Wikipédia como evidência válida - e esse foi também o caso dos vídeos subsequentes assinados por "La loca de mierda". Não obstante, o sucesso inesperado da vlogueira levou essa desconhecida cronista do âmbito privado exposto dessa maneira extravagante e engraçada ao universo do entretenimento profissional. Acompanhada pelo mesmo nome artístico, Pichot lançou-se em 2009 na MTV com uma série de capítulos televisuais (por exemplo, "Tolerância ou viver sozinha”), os quais receberam mais de um milhão de visitas quando foram colocados no YouTube.

No terceiro caso considerado aqui, há uma passagem do autêntico-efusivo, emocional - os numerosos visitantes dos vlogs da "Loca de Mierda" no YouTube são testemunhas de um derramamento húmido e fisiológico - para o âmbito auto-ficcional, sem que aparentemente haja um engano. Não haveria uma fraude como aquela que foi produzida em torno da jovem conhecida como lonelygirl15. A linguagem coloquial, misturada a xingamentos e gírias juvenis da mulher jovem de Buenos Aires ancorou sua atuação, a performance do self, no mesmo território autobiográfico que o ocupado pela fabricada e falsa vida de Bree e o de seu modelo real, a jovem americana Emily de paytotheorderofofof2. As crônicas audiovisuais de Malena Pichot residem no espaço semiótico do indicial, seu funcionamento depende da significação dos signos de existência. Há nesses vlogs um predomínio dos signos que se materializam como nossos sintomas, porque são reações viscerais, anímicas com respeito ao mun-

\footnotetext{
${ }^{11}$ Se consultarmos Wikipédia, na "enciclopédia livre" oferece-se a versão de que o primeiro vlog da Malena Pichot, de agosto de 2008, foi o resultado de um episódio sentimental real que a mulher argentina encenou com muito humor e auto-ironia. Para nossa abordagem conhecer a verdade definitiva sobre a natureza deste vlog não é pertinente, o fundamental é aquilo que Barthes (1968) chamou de 'efeito do real', deslocado agora para o âmbito (quase) documentário das redes sociais, de sites como YouTube ou Facebook.
} 
do circundante. Os signos indiciais que caracterizam os vlogs aqui considerados encontramse ancorados em um estrato mais reativo ou fisiológico do que simbólico. Nas respostas verbais ou glosas que se acumulam abaixo destes vídeos no YouTube, encontramos a manifestação de um forte desejo do público de acreditar que estes vlogs iniciais de Malena Pichot são verdadeiramente o real cru, que essas imagens e sons provêm diretamente do corpo afetado pela melancolia, pela solidão, e que as fortes emoções tingidas pelo humor absurdo da mulher jovem são registradas pela pequena webcam de seu computador, e de lá são transmitidas diretamente ao ciberespaço.

\section{Como revisitar a relação para-social na era de Youtube}

Nesta tentativa de compreender a estranha atração que exerce a representação do cotidiano nos vlogs autobiográficos do YouTube temos considerado três variantes. A terceira tem como recurso retórico a amplificação da autoparódia (= Pichot/La loca de mierda), que se origina em uma pessoa dotada de inegável histrionismo. Já consideramos a fascinação exercida por aquilo que é duvidoso, e que finalmente resultou ser uma fraude desenhada pelos produtores comerciais de Jessica Rose/lonelygirl15. 0 outro caso é o da atração indicial daquilo que é simplesmente real, factual, como acontece com a produção amadora dos vlogs de paytotheorderofofof2, produzidos na sua casa pela titubeante adolescente Emily. Uma possível explicação da forte atração é o apetite globalizado não apenas nem principalmente daqueles que visitam os canais do YouTube em grande número, mas os que usam as redes sociais em geral, com o intuito de entrar em um contato quase-físico com os signos indiciais do outro, ou ao menos com alguma coisa que se assemelhe ou aproxime ao real, à alteridade, mesmo em estado virtual. 0 índice é um tipo de signo que tem uma relação de existência com aquilo que ele representa, sua produção não é nem voluntária nem controlada (ex. o suor, ficar vermelho de vergonha ou ficar pálido). E por tal motivo que o índice é usado na mídia contemporânea para sustentar a promessa de que o espectador terá acesso ao elemento mais íntimo e oculto do ser humano, sua alma. 0 signo cujo funcionamento baseia-se numa relação existencial com aquilo que representa é o índice ou signo indicial. Nas mídias, este tipo de signo possui a função de dar acesso ao âmbito mais recôndito e autêntico do humano, qual seja, a contemplação da alma, de si mesmo. Esse é o maior troféu semiótico que aguarda no extremo do arco-íris confessional dos vlogs, onde quer que estes sejam produzidos. 
Há mais de meio século, dois psicólogos sociais propuseram um curioso tipo de relacionamento entre o espectador e a programação da então nascente televisão comercial nos EUA, no gênero do programa matinal de bate papo (talk show) cuja função é acompanhar o café da manhã das pessoas que estão em casa nesse horário. ${ }^{12}$ Entre a multidão anônima de espectadores e as personalidades midiáticas que cumprimentavam o público e faziam comentários triviais de modo amigável, sem-cerimônia alguma, criava-se, conforme estes dois especialistas, uma proximidade imaginária, um vínculo próximo à amizade, ao afeto:

Uma das características notáveis dos novos meios de massa - rádio, televisão, e cinema - é que eles criam a ilusão de uma relação face-a-face com quem realiza sua performance. As condições de resposta ao performer são comparáveis às que acontecem no grupo primário. As pessoas mais inacessíveis e ilustres são tratadas como se estivessem no círculo de nossos pares (...). Nós propomos chamar esta aparente relação face a face entre o espectador e o performer de uma relação para-social.

$\mathrm{Na}$ televisão, especialmente, a imagem que é apresentada torna disponíveis nuances da aparência e do gesto as quais a percepção social comum está atenta e com as quais a interação está harmonizada. (...) Quanto mais o performer (televisivo) parece ajustar sua performance à suposta resposta da audiência, mais a audiência tende a ter a resposta antecipada. Esse simulacro de troca conversacional pode ser chamado de interação para-social. (HORTON; WOHL, 1956, p. 215).

Proponho trazer essa proposta antecipatória de Horton e Wohl (1956) sobre o comportamento do público televisivo ao âmbito atual das redes sociais, e relacioná-la ao signo indicial, que Peirce define como:

Uma coisa real ou um fato que é um signo de seu objeto em virtude de estar conectado com ele como algo factual e também por ele se intrometer com muito vigor na mente, sem importar que ele seja interpretado como um signo. Ele pode simplesmente servir para identificar seu objeto e assegurar-nos de sua existência e presença. (CP 4.447 PEIRCE, 1931-1958)

Se pensarmos no primeiro vídeo de paytotheorderofofof2, o ligeiro e aparentemente incontrolável movimento do torso de Emily durante toda a duração desse vlog iniciático é provavelmente o resultado de uma reação física, a invisível e regular batida dos pés da jovem. Essa manifestação 'fisiológica', sintomática dos nervos experimentados pela jovem um signo indicial, do ponto de vista semiótico - constitui precisamente a evidência que nos garante a existência e a presença real de uma pessoa que é tão concreta e verdadeira como os nervos que se intrometem nessa crônica de aspecto improvisado, espontâneo de seu primeiro vlog no YouTube. Poderíamos pensar numa traição indicial do corpo de Emily à calma

\footnotetext{
${ }^{12}$ Um exemplo desse gênero é o programa matinal Mais você conduzido por Ana Maria Braga na Rede Globo.
} 
narrativa que seu testemunho em primeira pessoa claramente procura, e que constitui o material audiovisual que Bree - a lonelygirl15 - simulará em seus vlogs, e que ela vai levar ao paroxismo estético numa produção midiática profissional.

Um cronista da revista Wired descreve o rosto atrativo da suposta adolescente de 16 anos como a encarnação do ideal estético para esse meio de comunicação:

Há algo sobre Jessica Rose que a webcam ama. Suas sobrancelhas arrebatadoramente grandes e seu rosto pequeno e redondo são curvados e alongados pela objetiva de olho de peixe num pedacinho de beleza que encaixa perfeitamente numa janela instantânea na tela do computador. 0 rosto dela é um rosto feito para a tela do navegador. (DAVIS, 2006).

Também há uma série de diversos tiques e de gestos nervosos bem acompanhados, compassados pela trilha sonora, no caso de Bree, mas a impressão criada pelo conjunto aproxima-se mais a um filme comercial moderno feito sobre alguém semelhante a ela na vida real, embora não totalmente.

Por seu lado, quem se apresenta como "La loca de mierda" atinge um atraente clímax autoparódico e indicial em seu primeiro vlog. Depois dela ingerir algumas gotas homeopáticas de florais de Bach, que não produzem efeito algum, a jovem argentina empina o frasco inteiro; logo após de dizer a si mesma que o pior da tristeza já passou, seu corpo procede a contradizê-la estrepitosamente. Observamos e ouvimos seu choro desmesurado, um comportamento que é próprio do backstage, dos bastidores do universo audiovisual comercial, mas que essa mulher jovem, junto com todos seus congêneres no maior site audiovisual da internet teima em abrir para convidar todos os visitantes do YouTube a presenciar esse espetáculo, não importa o lugar que o espectador esteja no mundo. 0 vlog da argentina acontece numa área limítrofe entre o predomínio da significação indicial - o corpo que geme - e a prevalência do sentido icônico-simbólico, qual seja, a constante atitude de zombaria do próprio sofrimento expressado através de gestos que já são convencionais no cinema e na televisão.

0 resultado da abordagem sociosemiótica da análise proposta aqui permite-nos explicar a atração específica de um meio de comunicação que não somente habilita a horizontalidade de vocação democratizante - qualquer um pode responder com textos ou com imagens próprias a um vídeo no YouTube - mas oferece a visão das emoções de uma pessoa comum como aquele que assiste a esse vídeo. A significação indicial das imagens e dos sons do YouTube que selecionei para analisar neste artigo baseia-se na contiguidade material entre o signo perceptível e o objeto que ele representa: “o índice (...) como um dedo que aponta que 
exerce uma real força fisiológica sobre a atenção, de modo semelhante ao poder de um hipnotizador, e a dirige para um objeto particular de sentido" (CP 8.41 PEIRCE, 1931-1958, tradução nossa). Proponho a noção relação para-tátil para descrever esse efeito hipnótico indicial que as pessoas procuram quando assistem a essa classe de vlogs na internet. ${ }^{13}$ De modo semelhante ao efeito promovido no surgimento da televisão, qual seja, a proximidade social imaginária entre os telespectadores e aqueles destros executantes da função fática, ${ }^{14}$ em programas televisivos matinais, meio século depois as redes sociais também oferecem um contato imaginário, uma quase-proximidade física entre os visitantes e esses corpos não célebres dos vlogs na modalidade confessional. Assim, a derradeira barreira da interação parece ter sido derrubada pela queda crescente dos bastidores da humanidade, para nos deixar entrar amavelmente em sua intimidade banal.

\section{0 fascínio indicial: bem-vindos ao universo para-tátil das redes}

Aonde nos conduz essa virada indicial quando se trata das novas tecnologias da comunicação? Estamos seguindo em direção a uma condição de incredulidade cínica e generalizada, ou, pelo contrário, a uma nova Era de Aquário, na qual todos poderemos, eventualmente, estar em contato, quase-tátil, com todos? A resposta, proponho, não está em nenhum destes dois extremos, que resultam ser equivalentes: as tendências de pensar que vivemos em uma irreal e ubíqua Sociedade do Espetáculo (DEBORD, 1967), ou em um renascimento da ideia de McLuhan de uma "aldeia global" erram por falta de rigor, além de sua ideologia pessimista ou otimista no que diz respeito as mídias. Não parece viável afirmar que nada tem mudado nos tradicionalmente chamados meios de comunicação de massas, hoje designados como a ubíqua e muito poderosa "mediação" (LIVINGSTONE, 2008). A capacidade de enviar signos de todos para todos, e assim atingir potencialmente milhões de pessoas num tempo muito curto e com um custo extremamente baixo encontra-se nos antípodas daquela piada na véspera de Halloween feita pelo muito jovem e transgressor Orson Welles à frente de um grupo de atores, o Mercury Theater, em seu programa de rádio semanal.

\footnotetext{
${ }^{13}$ Há dois anos, eu assisti a um vídeo viral no YouTube cuja proposta estética foi uma variante não autobiográfica dessa relação paratátil. Seu título é "First Kiss". O vídeo foi visto por milhões de visitantes em sua primeira semana de exibição. Sua proposta é simples e inegavelmente indicial: vinte pessoas que não se conhecem são convidadas a se beijar na boca enquanto são filmadas. Para cumprir com a tarefa eles devem vencer um sentimento de insegurança que não é muito diferente ao observado nos vlogs analisados neste texto, quer na versão autêntica (paytotheorderofofof2; "la loca de mierda") ou na icónica-mimética (lonelygirl15).

${ }^{14}$ Trata-se daquela função da linguagem no modelo clássico de Roman Jakobson que serve para estabelecer o contato no início de qualquer comunicação. O conceito provém do antropólogo Bronislaw Malinowski, quem chamou de 'comunhão fática' toda expressão usada com esse fim, qual seja, a base da sociabilidade.
} 
O pânico pela suposta aterrisagem de marcianos em New Jersey não resultou homogêneo na população americana (CANTRIL, 1966), e ironicamente, conforme alguns teóricos, o incidente fez possível o sucesso prolongado de uma das teorias mais influentes da comunicação na modernidade, a chamada teoria dos efeitos limitados da mídia. Tudo levaria a pensar que aquele foi um exemplo do impacto vertical de um agente poderoso - a companhia proprietária daquele meio de massas - sobre um muito elevado número de ouvintes, a porção da população norte-americana que estava ouvindo o programa de rádio naquele 30 de outubro de 1938. Os espectadores-participantes no diálogo espontâneo que surgiu a partir do primeiro vlog que lonelygirl15 colocou no site do YouTube no mês de junho de 2006, são, em parte, co-protagonistas dessa saga identitária. 0 relato audiovisual foi primeiro indicial em seu efeito; tudo nesse vlog parecia apontar à presença de uma jovem comum, que em sua condição de internauta amadora entrou no imenso caleidoscópio do maior site audiovisual da internet. Depois da verdade ser revelada, o fenômeno foi apenas de natureza icônica: tratava-se de uma representação mimética de vlogs como aquele que mencionou lonelygirl15 na sua primeira produção. Quando descobriu-se que tudo aquilo fazia parte da produção encoberta de uma ficção para internautas, lonelygirl15 virou a primeira novela do site, como opinou com não pouco cinismo um dos produtores dos vlogs (BECKETT, 2007). Uma estratégia de marketing semelhante foi usada para apresentar o filme ficcional $O$ projeto da Bruxa de Blair (1999).

Os três vlogs analisados aqui compartilham o fato de serem os instrumentos audiovisuais que fizeram a fama de seus protagonistas e diferenciam-se porque dois deles possuem carácter indicial - aquilo que é percebido como genuíno ou real pelo público do YouTube enquanto o terceiro vlog considerado aqui somente imita os signos que possuem um elo existencial, o fáctico com o objeto que representam. A adolescente americana Emily, a responsável do vlog paytotheorderofofofof2, e a mulher argentina Malena Pichot, nos vlogs que ela assina como "La Loca de Mierda", oferecem acesso a seus sintomas, quer numa versão simples ou básica, quer em estilo autoparódico. Por sua vez, a moça que se apresentou como Bree, nos vlogs da lonelygirl15, limitou-se a fingir, a imitar o comportamento de uma adolescente norte-americana de 16 anos, e para isso, contou com a ajuda da equipe de produção. A atriz da Nova Zelândia produziu signos icônicos persuasivos (e atraentes) dos índices reais, que primaram pela ausência. 0 ato público de revelar os segredos da alma humana - hoje melhor conhecida como a identidade ou si mesmo (self) - supõe se aventurar em um âmbito microsocial explorado há já meio século na obra de Goffman; nesse espaço existe uma ten- 
são constante e constitutiva da pessoa que se desloca constantemente entre a fachada e os bastidores. Minha abordagem também incluiu revisitar a relação para-social descrita por Horton e Wohl há mais de meio século, que mimetiza convincentemente um vínculo afetivo inexistente, imaginário, entre celebridades da TV e os telespectadores nas suas casas.

As redes sociais promovem o alto consumo da significação indicial a distância, da ação de signos que se produzem no contato físico, ou quase-físico, no caso dos vídeos de pessoas comuns que narram sua vida cotidiana para dezenas ou milhões de visitantes-espectadores tão comuns como os criadores amadores do YouTube. Emily, Bree e Pichot, as três mulheres se convertem em estrelas indiciais ou, para maior exatidão, icônico-indiciais. Elas permitem, a aqueles que contemplam atentos, suas confissões mais ou menos espontâneas ou habilmente roteirizadas a sentir e a imaginar que todos eles podem tocar essas vidas narradas através de um parente distante da doméstica, quase privada home movie, a produção audiovisual caseira encarregada de documentar os marcos da vida de uma família burguesa, no século 20.

A inovadora 'affordance' (GIBSON, 1979) tecnológica habilita os internautas a fazer contato imaginariamente com o corpo indicial do outro escuro, nem anônimo nem famoso ainda, até transformá-lo em alguém luminoso, célebre durante algum tempo. Esse é um dos desfechos possíveis da relação para-tátil nas redes sociais hoje, mas aquilo que define essa nova classe de relacionamento midiático é o voraz interesse globalizado de experimentar um corpo a corpo que, sonha-se, poderia ir além da superfície plana, bidimensional do universo audiovisual. Tal é a experiência inédita na história humana produzida por uma expansão inusitada da comunicação no âmbito midiático das redes sociais.

\section{Referências}

ANDACHT, Fernando. Duas variantes da representação do real na cultura mediática: o exorbitante Big Brother Brasil e o Circunspeto Edifício Master. Contemporânea: Revista de Comunicação e Cultura, Salvador, v. 3, n. 1, p. 99-126, 2005.

ANDACHT, Fernando. Fight, love and tears: an analysis of the reception of Big Brother in Latin America. In: MATHIJS, Ernest; JONES, Janet (Org.). Big Brother International: formats, critics and publics. London: Wallflower, 2004. p. 123-139

BARTHES, Roland. L'effet du réel. Communications, Paris, n. 11, p. 84-89, 1968.

BECKETT, Miles. How YouTube created the video generation and changed my life. Time Magazine, New York City, may 2007. 
CANTRIL, H. The invasion from Mars: a study in the psychology of panic. New York: Harper, 1966.

COLAPIETRO, Vincent. Peirce's approach to the self. A semiotic perspective on human subjectivity. Albany: State University of New York, 1989.

DAVIS, Joshua. The secret world of lonelygirl. How a 19-Year-Old actress and a few struggling web filmmakers took on TV. A wired exclusive. Wired, San Francisco, Dec. 2006.

DEBORD, Guy. La Société du Spectacle, Paris: Buchet-Chastel, 1967.

DEBROCK, Guy. La Información y el estatuto metafísico de los signos. Comunicación y Sociedad IV, Pamplona, p. 53-64, 1991.

FORD, Aníbal. Navegaciones. Comunicación, Cultura y Crisis. Buenos Aires: Amorrortu, 1994.

FOREMSKI, Tom. SVW Exclusive: The identity of lonelygirl15. Silicon Valley Watcher, San Francisco, Sept. 2006. Disponível em: <http://www.siliconvalleywatcher.com/ mt/archives/2006/09/ the_identity_of.php>. Acesso em: 20 out. 2010.

GIBSON, James. The ecological approach to visual perception. Boston: Houghton Mifflin, 1979.

GINZBURG, Carlo. Señales: raíces de un paradigma indiciario. In: GARGANI, Aldo (Org.). Crisis de la razón: nuevos modelos en la relación entre saber y actividades humanas. Ciudad de México: Siglo Veintiuno, 1983. p. 75-128

GOFFMAN, Erving. The presentation of self in everyday life. New York: Anchor Books, 1959.

GOFFMAN, Erving. Behavior in public places: notes on the social organization of social gatherings. New York: The Free Press, 1963.

HEFFERNAN, Virginia. A single-camera dramedy, just in time for the fall season. The New York Times, New York, 28 June 2006.

HORTON, Donald; WOHL, Richard. Mass communication and para-social interaction: observations on intimacy at a distance. Psychiatry, London, New York, v. 19, n. 3, p. 215229, 1956.

LIVINGSTONE, Sonia. On the mediation of everything. Journal of Communication, Hoboken, New Jersey, v. 59, n. 1, p. 1-18, 2008.

PEIRCE, Charles Sanders. The Collected Papers of Charles Sanders Peirce. Cambridge: Belknap, 1931-1958. 8 v. Organização de Charles Hartshorne, Paul Weiss e Arthur Burks.

RANSDELL, Joseph. Teleology and the autonomy of the semiosis process. In: RANSDELL, Joseph. Arisbe: the Peirce gateway. 1989. Disponível em: 
<http://www.iupui.edu/ arisbe/menu/library/aboutcsp/ransdell/AUTONOMY.HTM>. Acesso em: 6 nov. 2011.

RUSHFIELD, Richard; HOFFMAN, Claire. Mystery fuels huge popularity of web's lonelygirl15: the videos are a hit on YouTube, but some wonder if the teen's posts are real or a marketing ploy. Los Angeles Times, Los Angeles, 8 Sept. 2006. Disponível em: <http://articles.latimes.com/2006/sep/08/entertainment/et-lonelygirl8>. Acesso em: 9 ago. 2010.

SCOTT, Anthony Oliver. How real does it feel? The New York Times, New York, 9 Dec. 2010.

\title{
A semiotic and indexical approach to identity in the age of YouTube
}

\begin{abstract}
The article studies the communicational and imaginary effects produced by either authentic or fake vlogs on YouTube through some famous cases in the history of that website where people upload and share videos. In many of those audiovisual productions there is a prevalence of indexical signs - the signification that arises from the contact of the sign with its object, such as footprints or symptoms. Nowadays, those signs are in high demand by the audience to satisfy a collective yearning for a body to body contact with the amateur producers - or those who present themselves as such - of autobiographical vlogs. The theoretical approach of Peircean triadic semiotic is used to analyze identity in the age of social media, and to analyze the public's doubt regarding what is authentic and what is not, the simulation of authenticity, since to entertain such a doubt seems inseparable from this kind of media experience.
\end{abstract}

\section{Keywords}

YouTube. Semiotic. Identity. Authenticity. Fraud. 